\title{
A Alma Brasileira na Alma dos Negócios: Propagandas de Violão na Revista 0 Violão
}

\author{
José Jarbas Ruas
}

Universidade Federal do Tocantins | Brasil

\begin{abstract}
Resumo: Constantemente associado ao discurso nacional e posto no panteão de signos urbanos o violão, neste artigo, é considerado como bem econômico produzido pelo emprego de força de trabalho dentro de um mercado comercial. Neste sentido, alinhamos problemas da Propaganda e Marketing para estudarmos à luz da Musicologia um conjunto imagético de propagandas musicais e extramusicais que foram publicadas pela Revista O Violão (1928-1929). Desse modo nos orientamos por quatro conceitos da área de Marketing: Produto, Praça, Promoção e Preço (KOTLER, 1998). Através da análise das peças publicitárias nos foi possível identificar traços do público-alvo da revista e mapear uma rede de estabelecimento comerciais que estavam vinculados ao periódico, qual denominamos Praça d'Violão.
\end{abstract}

Palavras-chave: Violão, Propaganda, Casas de Música, Rio de Janeiro, 1928-1929.

\begin{abstract}
Constantly associated with the national speech and placed in the pantheon of urban signs, the guitar, in this article, is considered as an economic product by the use of labor Power within a commercial market. In this sense, we aligned problems of Propaganda and Marketing in the light of Musicology a set of images of musical and extramusical advertisements that were published by "O Violão" (1928-1929). Thus, We are guided by four concepts in the Marketing área: Product, Place, Promotion and Price (KOTLER, 1998). Through the analysis of the advertising pieces it was possible for us to identify features of the magazine's target audience and map a network of commercial establishments that were linked to the periodical, which we call as Place of the Guitar.
\end{abstract}

Keywords: Guitar, Advertisement, Music Store, Rio de Janeiro, 1928-1929. 


\section{Propaganda é a alma do negócio. O célebre bordão do mundo dos negócios aplicados às 4 estratégias de Marketing e Vendas ecoa no imaginário coletivo no âmbito da cultura de 2 consumo na qual estamos inseridos. Derivado do latim propagare, segundo o dicionário} Priberam, o termo propaganda reporta seu significado a "um conjunto de atos que têm por fim propagar uma ideia, opinião ou doutrina”'. O Dicionário Aurélio (FERREIRA, 1993) define o termo como a "propagação de princípios, ideias, conhecimentos ou teorias; Publicidade”. Portanto, a propaganda tem por princípio propagar, multiplicar, reproduzir, estender, propalar-se, tornar público um conjunto de crenças, opinióes, ideologias, princípios e valores. Desse modo, teremos como principal fonte de referência um conjunto imagético de propagandas impressas de estabelecimentos musicais extraídas do periódico O Violão (1928-1929), publicado na cidade do Rio de Janeiro. Para além da perspectiva mercadológica que as propagandas nos servirão, elas nos permitiram trazer à tona 1) a composição de uma rede de estabelecimentos concorrentes que contribuíram para a difusão e a circulação do instrumento na cidade; e 2) conhecermos o públicoalvo da revista a quem ela esperava se dirigir a partir de suas propagandas.

As peças publicitárias em si não podem afirmar com precisão se o público-alvo almejado de fato era o consumidor do conteúdo publicado, entretanto, elas nos fornecem breves vestígios do horizonte de expectativas a quem os editores alinhavam sua proposta e estratégia de venda de espaço para divulgação nas páginas do periódico. Desse modo, a assertividade da comunicação entre estabelecimento e consumidor expresso pelo conjunto de signos representados na peça publicitária tem por princípio alcançar de modo claro e objetivo com a mensagem transmitida os desejos, necessidades e anseios que motivem emocionalmente o consumidor a desprender de recursos para adquirir o produto e/ou serviço prestado.

Embora a divulgação dos produtos e serviços seja essencial para atrair a atenção dos leitores do periódico, o anúncio serve também como uma importante fonte de receita somada a venda de assinaturas da revista para composição de caixa de modo a garantir que os custos de produção para a editoração e circulação do periódico pudessem alcançar o público nas praças comerciais.

Outro aspecto que podemos destacar é que a divulgação é fundamental para dar visibilidade, consolidar o posicionamento e a imagem da marca dentro de um mercado-alvo e desse modo, garantir

\footnotetext{
${ }^{1}$ Definição de propaganda em: https://dicionario.priberam.org/propaganda. Acesso em: 31 ago. 2020.
} 
a possibilidade de expandir os negócios ante à concorrência. Logo, espera-se que os produtos em divulgação na propaganda sejam reconhecidos por suas características, benefícios e vantagens, de modo a destacar o diferencial da empresa no mercado.

Que crenças, princípios, opinióes e valores as peças publicitárias sobre violão pretendem transmitir nesta revista? Que signos elas comportam e que nos permitam alcançar o público-alvo da revista O Violão? Que informações podemos extrair acerca do mercado de vendas de violão no centro da cidade do Rio de Janeiro?

\section{Violão enquanto produto na praça comercial carioca}

Nas páginas da Revista $\mathrm{O}$ Violão um conjunto de frases compóem o imaginário coletivo que remontam a colocar o instrumento no panteão dos signos urbanos nacionais. "Companheiro inseparável do cancioneiro apaixonado, como mavioso repositório das manifestações da alma”. “Instrumento mais sincero e generoso". É aquele que “tem guardado os segredos de fidalgos e plebeus". "Nenhum outro [instrumento] tem a sua sintonização tão acorde à alma humana". "Instrumento predileto que tem sido, durante séculos, o encantamento da alma nacional". Dispóem entre seus predicados a sonoridade e a doçura com "o seu modo todo particular de seduzir e falar à alma brasileira” (O Violão, n.1, 1928).

Heitor Modesto, membro do Icarahy Violão Club descreve o instrumento da seguinte maneira

O violão é, por excelência, a música nacional. É a música da nossa raça emigrada para a América, para o Novo Mundo. Ele é irmão da guitarra - como a modinha é irmã do fado português. Todos tem na mesma alma a mesma dolência, o mesmo sonho, a mesma ânsia. A diferença apenas é que a guitarra e o fado passaram e o violão e a modinha cantam, languidamente, no ritmo tropical, a nossa mulher, o nosso amor, no cenário perturbador da natureza em triunfo, na vida de manhã. (O VIOLÃO, n.2, 1929, p. 34)

Todas essas frases citadas acima nos condicionam a entender o simbolismo em torno do violão. Mas para além dos signos que o instrumento comporta no imaginário coletivo dos colaboradores da Revista, o violão também pode ser compreendido enquanto bem material tangível que requer o emprego de força de trabalho para ser produzido. Nesse sentido, o violão é envolvido num fator de escolha uma vez que os recursos para sua produção são escassos e exigem esforço para serem obtidos. 
Enquanto bem econômico, o violão exerce um papel de utilidade de modo a satisfazer uma necessidade humana que se insere no grau das escolhas determinadas pelos anseios da sociedade. E quando um bem útil é aproximado dos signos, simbolismos e sentimentos de conexão constrói-se uma estratégia de geração de valor agregado.

Portanto, vamos abordar o violão por sua perspectiva mercadológica e para que ele seja alçado ao consumo existem mecanismos aplicados ao universo dos negócios que visam satisfazer as necessidades humanas da melhor forma possível. À luz da estratégia de mercado nos utilizaremos dos 4 "P" do Marketing que foram desenvolvidos inicialmente por Jerome McCarthy e amplamente difundidos na obra de Philip Kotler (1998). Logo, nas seçôes que se seguem abordaremos oportunamente os conceitos de Produto, Praça, Promoção e Preço.

Ao longo de sua obra Kotler definiu os $4 \mathrm{P}$ do Marketing como um conjunto de ferramentas essenciais para que as empresas pudessem atingir seus objetivos de Marketing em um mercado alvo.

De acordo com Kotler (1998), produto é um bem produzido para um determinado mercado com a finalidade de ser apreciado, usado e/ou consumido. Seu objetivo principal é satisfazer através de sua oferta um desejo, necessidade e/ou demanda inerente ao consumidor. Diferente de um serviço, que tem por prerrogativa ser imaterial, por não dispor de forma física, o produto envolve materialidade, já que pode ser visto, tocado e sentido pelo cliente, o que é o caso do violão.

Junto ao produto uma série de atributos simbólicos e emocionais pode ser atribuída de modo a estreitar a relação do cliente com o produto e orientá-lo na tomada de decisão no ato da compra. Esses atributos visam sensibilizar o imaginário do consumidor a fim de proporcionar diferenciação e no campo da propaganda, gerar valor agregado ao produto de modo a atender as expectativas identificáveis do público-alvo em um determinado mercado.

A composição do mercado carioca de fabricação e comercialização de violão dispóe de uma série de atores que compõem a cadeia produtiva do instrumento desde a produção, distribuição e consumo. Neste texto, nos concentraremos em expor uma rede comercial que esteve associada à Revista O Violão através da veiculação do periódico, mas também por usá-la como canal de comunicação com seus potenciais consumidores. A esta rede de estabelecimentos musicais atribuiremos o nome de Praça d'O Violão.

O segundo P do Marketing definido por Kotler é Praça que também é conhecido como ponto 
de venda (PDV). Ou seja, o local do estabelecimento. A praça é o local onde ocorre a movimentação física em que um determinado produto é disponibilizado e geram a ocorrência de relaçôes de troca entre quem produz a oferta e quem a consome.

Como a venda pode ser vista como uma atividade essencialmente emocional, como destaca a Psicologia de Consumo, a identidade visual do estabelecimento contribui para a promoção de um diferencial competitivo e atrativo para as vendas. Somada à aparência estética do ponto, a sua implantação requer também conhecimento do perfil demográfico da região, a fim de garantir proximidade com o público-alvo, gerar conhecimento atualizado sobre o comportamento de compra e os interesses dos consumidores. Nesse sentido, a proximidade com a concorrência permite que as empresas possam usufruir do fluxo de consumidores gerado por um estabelecimento pioneiro na localidade considerando a existência de um público que almeja consumir o produto naquela região.

A praça d'O Violão forma-se, portanto, da reunião de nove casas de música localizadas na região central da cidade do Rio de Janeiro (Ver Tabela 1). Elas estavam geograficamente próximas a principal estação de bondes no Largo da Carioca e da região de entretenimento da cidade, na praça Tiradentes.

TABELA 1 - Estabelecimentos musicais cariocas citados na Revista O Violão

\begin{tabular}{lcc}
\hline & Endereço & Fundação \\
\hline Ao Cavaquinho de Ouro & Rua da Uruguaina, 137 & 1894 \\
Casa Euterpe & Av. Rio Branco, 88 & 1906 \\
Casa Arthur Napoleão & Av. Rio Branco, 122 & 1869 \\
A Guitarra de Prata & Rua da Carioca, 37 & 1887 \\
Casa Carlos Werbs & Rua da Carioca, 47 & 1851 \\
Ao bandolim Nacional & Rua D. Pedro I, 20 & 1915 \\
Casa Bevilacqua & Rua do Ouvidor, 155 & 1846 \\
Casa Vieira Machado & Rua do Ouvidor, 179 & $189 ?$ \\
Aoclarim universal & Rua Marechal Floriano Peixoto, 27 & 1915 \\
\hline
\end{tabular}

Fonte: AUTOR (2020).

\section{Marketing, estratégias e táticas aplicadas em vendas}

A fim de fundamentarmos um campo teórico-analítico que nos sirva de base para problematizarmos alguns pontos relevantes nos anúncios publicados na revista O Violão (19281929), nos aproximaremos dos preceitos do Marketing por considerá-lo uma das áreas que 
fundamenta estratégias empresariais de venda. Com isso, não estamos afirmando que as Casas de Música dispunham necessariamente de um setor que planejasse uma política de divulgação e vendas. Esse estreitamento teórico visa uma aproximação conceitual com os problemas dessa área que nos permitiram lançar algumas reflexóes sobre as peças analisadas e que acabaram por nos fornecer subsídios para observarmos por um novo ângulo crítico e problematizador estes anúncios.

Dito isso, pontuaremos a seguir os limites do Marketing de modo a constituirmos um panorama que considere a reflexão da elaboração de planos estratégicos e táticos aplicados às vendas e representados pelas peças publicitárias. Nesse sentido, o conceito de Marketing nos remete a considerar a interdependência de uma perspectiva tridimensional: funcional (objeto e objetivo), gerencial (processo administrativo e prático) e filosófica (orientação para ação administrativa). Kotler (1998, p. 27) define Marketing como "um processo social e gerencial através do qual, indivíduos e grupos obtêm aquilo que desejam e de que necessitam, criando e trocando produtos e valores uns com os outros”. Ao considerar as metas estabelecidas pela organização, Kotler considera que o Marketing contribui para tornar os processos gerenciais mais efetivos e eficazes para suprir as necessidades de um mercado-alvo. Czinkota, Dickson, Dunne e Griffin (2002), alçam as raízes do Marketing em sua orientação filosófica ao dedicarem-se especificamente no consumidor. Logo, ao concentrar seus esforços na produção e na forma de direcionar a venda, o Marketing visa entender e servir as necessidades, desejos e anseios do consumidor. Na mesma direção, Rocha e Christensen (1999) ressaltam que o Marketing exerce uma função gerencial a fim de ajustar a oferta de organização de ferramentas específicas centradas em princípios. Enquanto orientação administrativa, o Marketing pode ser visto como um processo de regulação da oferta e da demanda de bens e serviços direcionando as vendas alinhado-as as expectativas do consumidor.

Casas (2007) pontua a abrangência do Marketing no que concerne às relaçóes de valor de troca. Sendo esta relação orientada para a satisfação (desejo e necessidade) do consumidor, de modo que alcance o objetivo estratégico mútuo, ou seja, da empresa e do indivíduo consumidor, espera-se que o resultado cause impacto positivo no meio de atuação e proporcione bem-estar social. Nessa mesma vertente, de benefício mútuo, Nickles e Wood (1999) pontuam o estabelecimento e a manutenção das relaçóes de troca, qualidade e valor no processo de gestão de Marketing.

Sendo uma função empresarial estratégica, Macheline, Rojo e Psillakis (2003) entendem que o 
Marketing tem seu olhar voltado para o mercado de modo a criar continuamente valor para seus clientes e com isso, que a empresa possa alcançar vantagem competitiva e longevidade no mercado.

A partir dos conceitos expostos acima podemos ressaltar que o Marketing propóe uma filosofia de ação para a empresa, tendo por base um conjunto de técnicas e instrumentos que lhe permitam analisar as características específicas do mercado e assim estimular positivamente a facilidade de troca de produtos e serviços ao criar relações mutuamente benéficas entre empresas e consumidores. Logo, a gerência de Marketing deve ter uma visão holística ao avaliar os recursos corporativos que estão a sua disposição, de modo a estabelecer objetivos e estratégias de impacto no mercado que possam estimular as vendas pela atração de prospects. Compete ainda ao Marketing controlar e avaliar os resultados de modo a perceber a necessidade e a implementação de açôes corretivas no plano geral de vendas. Nesse sentido, no âmbito da venda, as estratégias e táticas desenvolvidas devem proporcionar uma nítida percepção ao consumidor que represente: confiança, credibilidade e qualidade.

Oriundos do campo semântico militar os conceitos de estratégia e tática foram incorporados ao léxico de outras áreas. Dentro do jogo de renovação urbana Lefebvre (2011 [1968], p. 113) pontua estratégia como um plano maior fundado na hierarquia das variáveis a serem consideradas no âmbito tático e prático. Certeau (1998 [1980], p. 46), ao estudar o sistema de operações heterogêneas do cotidiano enquanto material das práticas, pontua estratégia como “o cálculo das relações de força que se tornam possíveis a partir do momento em que um sujeito de querer e poder, é isolável de um ambiente”. Por tática, Certeau (1998 [1980], p. 47) posiciona-se ao considerá-la dentro do campo da possibilidade uma vez que depende da perspicácia analítica das circunstâncias do tempo impostas pela sensibilidade da vigilância para apurar a possibilidade de ganho diante dos acontecimentos da ocasião. Desse modo enquanto a estratégia prevê de modo global o cálculo de seus passos para a conquista do objetivo, a tática apropria-se da circunstância do momento para agir e pôr em ação o plano. E nesse sentido, consideraremos as propagandas como uma das possíveis ações táticas que compuseram um plano estratégico maior de vendas em suas respectivas organizações.

Neste sentido, o terceiro P do Marketing é a promoção. Entende-se por promoção as estratégias e ferramentas de comunicação que buscam promover o produto de modo a fazê-lo chegar ao públicoalvo e incentivar o consumidor a compra. Logo, qualquer canal que tenha por objetivo expor uma marca, produto ou serviço no mercado trata-se de uma promoção. Neste ponto, a comunicação social 
une-se a Propaganda e ao Marketing para desenvolver a assertividade do discurso com o objetivo de atingir o consumidor e cumprir com os propósitos e objetivos que estão alinhados aos valores da empresa. A assertividade das campanhas de promoção visa contribuir para a difusão da marca a fim de posicioná-la estrategicamente no ambiente mercadológico e na mente dos consumidores.

\section{Indícios para reconhecer o público-alvo da revista}

Considerando o grau de assertividade necessária nas ações publicitárias conforme sugere o conceito de promoção, que indícios podemos perceber explicita e implicitamente nas páginas e nos anúncios publicados pela Revista $\mathrm{O}$ Violão?

Uma análise atenta ao formato do periódico, observando seu tamanho, estética, imprensa gráfica, colunas e principalmente os anúncios publicados tem muito a revelar sobre a audiência d'O Violão.

A revista foi um periódico de perfil técnico e consequentemente de valor mais elevado que as de gênero comum (atualidades e ilustradas) de seu tempo. O preço de $5 \$ 000$ réis mostra-se figurativo se comparado ao preço dos jornais que eram vendidos entre $\$ 100$ e \$200 réis e de revistas ilustradas semanais como a Cruzeiro com preço de capa em $1 \$ 000$ réis.

Para além do fator preço, a revista era impressa em papel couché e com excelente acabamento gráfico como descreve a crítica do Jornal O Globo em 06 de dezembro de 1928 e em 17 de janeiro de 1929. Trazendo em suas páginas conteúdo com exercícios técnicos da Escola de Tarrega, cançôes populares e seus acompanhamentos, e peças para repertório de concerto a Revista veio à tona com o objetivo de orientar o processo de estudo entre os amantes do instrumento. Para tanto, aborda conteúdos em torno das nomenclaturas de mão direita e mão esquerda na Coluna Violão ao alcance de todos; e ilustra para seus leitores o posicionamento adequado para a prática do instrumento.

A revista segmenta seu nicho de mercado em três micronichos que potencialmente pudessem estar interessados em aprender o instrumento, e para tanto adota diferentes metodologias. Neste sentido, oferece o estudo por tablatura para aqueles que não dispunham dos conhecimentos básicos de leitura da partitura e praticavam o acompanhamento do instrumento pelo ouvir. O segundo público era àqueles dedicados ao violão de acompanhamento de canções com melodias simples. Já o 
terceiro público era àqueles propensos ao alinhamento técnico e filosófico do estudo do instrumento através da Escola Moderna de Violão de Francisco Tarrega.

A coluna "Nossos amadores" conta com um número expressivo de fotos de jovens senhoritas e, em menor número, de rapazes da "boa sociedade" carioca, paulista e baiana posando com seus violóes. A Revista também cobriu uma série de eventos sociais ${ }^{2}$ e $\operatorname{concertos}^{3}$ que ocorreram entre 1928 e 1929 na qual o instrumento esteve em primeiro plano.

Para além da obviedade na propaganda de produtos e estabelecimentos musicais da cidade do Rio de Janeiro, Niterói, São Paulo e Bahia que se fazem representados nas páginas da revista um conjunto variado e curioso de outros produtos e serviços ocuparam as páginas da revista em seus 10 volumes.

No âmbito da venda de aparelhos sonoros a loja A. L. Moraes anuncia seus novos receptores de rádio de corrente alternada, o ERLA, como sucesso de vendas. A Oficina de Rádio A. F Moreira, vizinha à sede da revista, na Rua São José 54, 2o andar, “anuncia que faz e concerta aparelhos de rádio com perfeição” (O VIOLÃO, n. 4, n. 5, n. 7, 1929). A Casa Victor também divulga sua nova e moderna Vitrola Victor Orthophonica para o deleite dos apreciadores de música.

No campo da impressão literária a Ediçôes Pimenta de Mello \& Cia divulga uma lista de suas publicaçóes que tocam a bibliografia científica com temas da Sociologia, Anatomia, Patologia, Oftalmologia, Matemática, Direito e Química Orgânica. Estes títulos dessa seção podiam ser adquiridos entre $20 \$ 000$ e $40 \$ 000$ réis. O estabelecimento contava ainda com títulos no campo da literatura com preços entre $2 \$ 000$ e $8 \$ 000$ réis, da didática e das variedades.

A Sul-América Seguros aparece divulgando-se como a maior companhia de seguros de vida da América do Sul e exibindo seus excelentes resultados no exercício do ano 1928 - 1929 (O VIOLÃO, n. 4, 1929, p. 22).

No âmbito das vestimentas masculinas, duas camisarias: $\mathrm{O}$ cearense, roupas sob medida. E a Rose, camiseiro da elite (O VIOLÃO, n. 6, 1929, p. 4). Para o público feminino a Parc Royal desponta

\footnotetext{
${ }^{2}$ Eventos no Cassino Beira Mar (O VIOLÃO, n.3, 1929), encontro do Icarahy Violão Club (O VIOLÃO, n. 1, 1928, p. 13), as noites do Tijuca Tennis Club (O VIOLÃO, n.1, 1928, p. 27); Theatro Lyrico.

${ }^{3}$ A série de concertos de Juan Rodriguez no Instituto Nacional de Música (O VIOLÃO, n. 6, 1929, p. 6) e os concertos de Sainz de la Mazza no Theatro Municipal (Artes e Artistas, O VIOLÃO, n. 6, p. 12); recitais de Olga Pragner (O VIOLÃO, n.7, 1929, p. 11; O VIOLÃO, n. 9, 1929, p.25); recital da miss Ipanema Laura Suarez (Recital de Violão e canto. O VIOLÃO, n.5, 1929, p.28);
} 
como a grande fornecedora de elegância para todo o Brasil. A Geladeira Kelvinator é divulgada com duas jovens senhoras no momento do flanêur observando o item que proporciona "saúde, conforto, contentamento e economia” e com vendas à longo prazo (O VIOLÃO, n.3, 1929, p. 2). A loja Ao Trovador, antiga Casa Dol, anuncia-se como a primeira casa do Brasil em artigos para crianças e informa que dispóe de novidade também para as senhoras (O VIOLÃO, n.1, 1928, p. 26). Atendendo ainda ao público infantil, a Matricaria Dutra, mostrava-se como uma solução para ajudar na dentição dos pequeninos (O VIOLÃO, n.1, 1928, p. 26).

Para cuidar dos problemas de pele causados pelo terrível calor dos meses de verão na cidade, Suol, "infalível contra o suor excessivo, nas coceiras e frieiras", disponíveis nas melhores farmácias da cidade. E para o frio de julho? “Foi-se a bronquite! Estou forte! Já tomei para num bródio; Zombarei da própria morte enquanto houver o PROMODIO!” (O VIOLÃO, n. 7, 1929, p. 10).

Duas marcas de cigarro registraram anúncio, a Jockey Club e o Cigarro Rio Chic, voltado ao público feminino. A propaganda dizia: “o Cigarro Rio Chic é nos lábios da mulher a saudade de um beijo. Um beijo do seu amado! Tal é a sensação da mulher chic ao fumar os cigarros Rio Chic" (O VIOLÃO, n.1, 1928).

A Loja com maior ocorrência de publicidade na Revista é a Macedo \& Irmão. Uma loja de instalações sanitárias de luxo. A Casa informa que dispunha em estoque um grande sortimento de artigos sanitários, com montagem completa e sendo capaz de fornecer aos seus consumidores banheiros de luxo, belas louças sanitárias e banheiras de luxo, além de realizar instalações de água, gás e esgoto.

Lewis Mumford (1961 [1938]) ao abordar a cultura das cidades descreve a formação das metrópoles no início do século XX ressaltando o inchaço populacional. Com o crescimento acelerado e desordenado nestas cidades, Mumford destaca os custos que são inerentes para que a vida nas metrópoles possa existir. Um deles é o custoso processo de canalização de água de modo que esta possa ser bombeada do local de armazenamento originário e conduzida por quilômetros de canos conectados a adutoras que vão distribuir a água a fim de abastecer as residências. As redes de esgoto aparecem como forma de tratamento para os dejetos e proporcionar um ambiente saneado. Neste contexto, o quarto de banho, ou o banheiro ganha destaque. Segundo o autor 
esse nível de higiene corporal jamais fora atingido antes, mesmo entre as classes superiores; o ritmo de introdução foi, sem dúvida, apressado pela necessidade de anular os efeitos desagradáveis ou perigosos da vida metropolitana. Como a instalação do banheiro torna-se mais complicada, o custo da construção da moradia aumenta; daí estabelecer-se uma restrição cada vez maior de espaço entre as classes médias, que são as primeiras a adotar a lavagem e o banho frequentes como necessidades (MUMFORD, 1961 [1938], p. 251).

Recobrando os termos luxo, elite, elegância, chic citados nos anúncios anteriores e somadas a instalação de banheiro, considerando o valor de capa da revista podemos considerar que a revista não estava ao alcance de todos, e mais provavelmente buscava ter como interlocutor a classe média e alta.

\section{Propagandas de violão}

Adentrando ao universo das propagandas das Casas de Música que compunham a Praça d’O Violão, iniciaremos pela Ao Bandolim Nacional (ver Fig. 1) já que ela revela uma informação importante: preço de instrumentos. Em geral, a maioria dos anúncios publicados não revelam os preços dos itens em divulgação. Dentro dos anúncios que coletamos na Revista, apenas dois fazem referência ao preço de um violão. Este, em especial, conta com muitos elementos imagéticos. Nele podemos observar a carta de produtos da Casa ao pôr em oferta os seguintes cordofones: violinos, arcos, violóes, violas, bandolins, bandurras, guitarras e cavaquinhos. O preço em questão refere-se ao ponto de partida praticado no catálogo iniciado na ordem de $22 \$ 000$ réis, já os bandolins eram comercializados à partir de $40 \$ 000$. Isso nos faz sugerir que a Casa dispunha de outros modelos em estoque e que praticava preços superiores a este. Neste anúncio podemos ver a menção ao valor praticado em guitarras com estojo, à $90 \$ 000$ réis; e violinos com estojo à $120 \$ 000$. O anúncio faz menção à associação do estabelecimento com a oficina de concertos de instrumentos de E. P. Malheiros dando ênfase na especialidade em estabilizar violinos e arcos.

O anúncio informa que o estabelecimento "recebe diretamente da Europa todos os artigos pertencentes a instrumentos de música” uma informação que pode sugerir a conexão com o que havia de mais atual, moderno e de bom gosto no cenário internacional da música. O estabelecimento ainda se coloca como especialista em cordas e praticante da venda por atacado e varejo. 
FIGURA 1 - Anúncio do estabelecimento Ao Bandolim Nacional. No canto superior direito, imagem de um bandolim. Em destaque na parte superior aparecem o nome do estabelecimento, seguido abaixo dos produtos da carta. No canto esquerdo, aparecem as informações relativas a importação com Europa. Do lado direto, menção a oficina de E. P. Malheiro. Os preços informados aparecem na parte inferior direita da arte de divulgação.

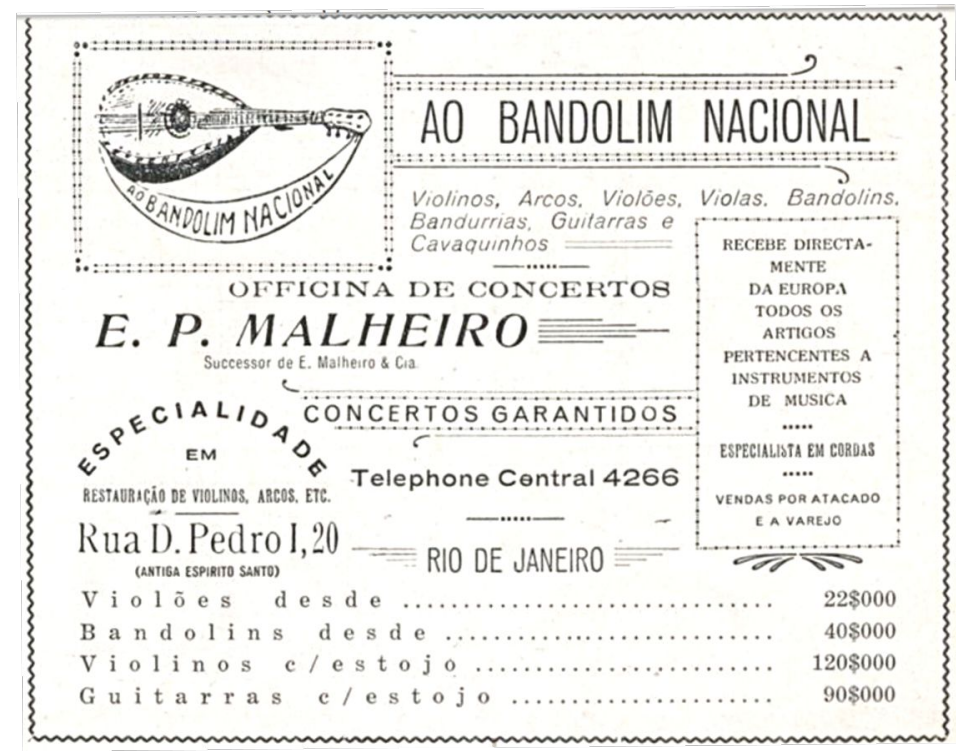

Fonte: O VIOLÃO (1928, p. 19)

O segundo anúncio que nos fornece uma dimensão acerca do preço de comercialização de violóes é da Casa O Cavaquinho de Ouro. Em seu anúncio publicado no primeiro volume da Revista O Violão a marca apresenta dois modelos: “Typo Cavaquinho de Ouro” e o “Typo Valenciano”. O primeiro modelo dispunha da série N.3 cotado entre $30 \$ 000$ e $250 \$ 000$, o N.2 entre $60 \$ 000$ e $300 \$ 000$ e o N.1 entre 70\$000 e 600\$000. Outro modelo anunciado é o “Typo Valenciano, a última palavra na indústria nacional. Preferido pelos nossos exímios violonistas”. Este segundo modelo estava precificado em 3a Classe, tipo no 1 de $150 \$ 000$ a $700 \$ 000$ e o tipo no 2 de $120 \$ 000$ a 300\$000. Já o modelo 2 2 Classe, tipo extra, no 1 estava cotado entre $500 \$ 000$ a $700 \$ 000$ e o no 2 nos mesmos valores (O VIOLÃO, n.1, 1928).

A fim de definir oportunamente o último "P do Marketing” proposto por Kotler, preço é o valor desprendidamente pago pelo consumidor da marca, de modo a lhe permitir tomar posse do produto. Segundo Rackham (2011 [1989]), o preço representa a variável que mais influencia o consumidor no momento da tomada de decisão da compra. Isso porque o consumidor deve ser capaz de perceber claramente a relação custo-benefício, ou seja, perceber que o produto atende aos seus critérios de compra, dentro de um valor de troca satisfatório e em melhores condiçóes que o proposto 
pelos estabelecimentos concorrentes. Sendo assim, no universo mercadológico, a política de preço do estabelecimento deve estar em consonância com o que é praticado no mercado e com a estratégia de alcance mercadológico da organização. Diante dos preços expostos pelos dois anúncios nos cabe a seguinte a pergunta: quem podia comprar um violão?

No que toca a formação de preço de violóes existem todos os custos inerentes à fabricação, adicionados aos gastos de distribuições, alíquotas tributárias e a lucratividade dos agentes envolvidos na cadeia de produção até chegar ao consumidor.

A fim de criar um parâmetro sobre o Índice de Custo de Vida, recorri enquanto fonte auxiliar ao jornal A Classe operária: Jornal de trabalbadores feito para trabalbadores (1925-1928), para verificar a remuneração da força de trabalho operária. Nestas páginas encontramos menção a alguns valores pagos a certas categorias que lutavam por melhorias salariais. O Jornal informa, por exemplo, que a diária de um operário do campo até o ano de 1914 era na ordem de $\$ 600$ réis (A Classe operária, Rio de Janeiro, 31. Mai. 1925, p. 1). A fim de dar uma demonstração aos seus leitores sobre as dificuldades de se manter na cidade, o jornal informou apenas os custos de uma família operária com as despesas da casa e alimentação (ver Tabela 2), ou seja, sem considerar a necessidade de vestuário, eventuais enfermidades e a educação dos filhos de um trabalhador. A nota de despesas foi enviada por um foguista ${ }^{4}$ no ano de 1925, que era responsável pelo sustento da esposa e dois filhos. Sua despesa mensal era:

TABELA 2 - Despesas básicas de alimentação e casa um operário na cidade do Rio de Janeiro em 1925

\begin{tabular}{lc}
\hline Item & Valor pago \\
\hline Aluguel do quarto & $60 \$ 000$ \\
Pão(1kg por dia a 1\$200) & $36 \$ 000$ \\
Café $(4 \mathrm{Kg}$ a $5 \$ 600)$ & $22 \$ 400$ \\
Açucar (15kg à 1\$400) & $21 \$ 000$ \\
Feijäo mulatinho (15Kg a \$800) & $12 \$ 00$ \\
Farinha (8kg a 1\$000) & $8 \$ 000$ \\
Arroz (15Kg a 1\$200) & $18 \$ 000$ \\
Carne ou peixe $(1 \$ 500$ por dia) & $45 \$ 000$ \\
Banha (4kg a $7 \$ 000)$ & $28 \$ 000$ \\
Batatas (12kg a 1\$000) & $12 \$ 000$ \\
Despesas de quitanda (legumes, verduras e temperos) $\$ 800$ por dia & $24 \$ 000$ \\
\hline
\end{tabular}

\footnotetext{
${ }^{4}$ Funcionário incumbido da alimentação, vigilância e manutenção de uma caldeira à vapor.
} 
TABELA 2 - (cont.) Despesas básicas de alimentação e casa um operário na cidade do Rio de Janeiro em 1925

\begin{tabular}{lc}
\hline Item & Valor pago \\
\hline Despesa de mindezas de armazém (sal, cebola, alho, vinagre, pimenta do reino, azeite, fósforo, & $36 \$ 000$ \\
sabão e outros) & $36 \$ 000$ \\
Carvão (1\$200 por dia) & $358 \$ 000$ \\
Total & $235 \$ 000$ \\
Ordenado mensal & $123 \$ 400[\mathrm{sic}]$ \\
Déficit & \\
\hline
\end{tabular}

Fonte: A classe operária (Rio de Janeiro, 06.jun.1925)

Com um déficit substancial no orçamento da família, o periódico informou que a esposa do foguista trabalhava até tarde da noite em frente a sua máquina de costura para contribuir com a renda da casa e honrar os compromissos da família.

A fábrica de tecidos Moinho Inglês, localizada na região do cais da cidade do Rio de Janeiro, dispunha de dois turnos de trabalho um entre $18 \mathrm{~h}$ e $6 \mathrm{~h}$. Para os operários desse horário a jornada de trabalho semanal era de 60 horas. O segundo turno era realizado entre $7 \mathrm{~h}$ e $16 \mathrm{~h}$ com jornada semanal de 72 horas. Segundo o jornal, os operários ganhavam $6 \$ 000$, as operárias $7 \$ 000$ e os meninos $3 \$ 000$ (A classe operária - RJ, 13.jun.1925).

As condições da classe operária tecelã tiveram apenas em 1918 uma ligeira melhora salarial. Eulália Lobo (1971) no estudo “A evolução dos preços e padrão de vida no Rio de Janeiro” informou que um operário de fábrica de tecido no Rio de Janeiro ganhava em média no ano de 1903 o soldo de $78 \$ 000$. Os custos com o pagamento do aluguel de uma casa, para uma família de quatro pessoas chegavam à ordem de $60 \$ 000$ réis por mês, para um estabelecimento que era propriedade da própria fábrica. Diante de um custo tão elevado o fato exigia que a mulher e os dois filhos menores também trabalhassem na empresa para manter os custos da família. Embora no ano de 1908 seja possível observar uma redução no preço do aluguel nas moradias de fábricas para famílias operárias na ordem de $8 \$ 000,10 \$ 000$ e $30 \$ 000$, os salários também foram reduzidos chegando à ordem de $\$ 600$ a $1 \$ 000$ pelo dia de trabalho (LOBO, 1971).

\footnotetext{
${ }^{5}$ Fonte: <http://bibliotecadigital.fgv.br/ojs/index.php/rbe/article/viewFile/67/6249> Acesso em: 31.ago.2020. Lobo, Eulalia Maria Lahmeyer et all. Estudo das categorias socioprofissionais, dos salários e do custo da alimentação no Rio de Janeiro de 1820 a 1930. Revista Brasileira de Economia. 27 (4): 133, out./dez. 1973
} 
Lobo (1971) informa ainda que dentro da segunda metade da década de 1920 o preço dos itens básicos de alimentação sofreu alterações:

O preço interno do café apresenta declínio em 1926-1927, alta relativa em 1928 e baixa em 1929-1930; o do arroz baixa de 1926 a 1929; o do açúcar mascavo de 1925 a 1927 e de 1929 a 1930. O preço da farinha de trigo declina somente em 1930; o do bacalhau em 1930; o da manteiga de 1928 a 1930; o do feijão de 1929 a 1930; o da farinha de mandioca de 1926 a 1927, mantendo-se baixo até 1930. (LOBO, 1971, p. 249).

Pondo em contraste o ordenado mensal do operariado tecelão, os preços de violão tal qual anunciados pela Revista exigiriam um montante considerável destes profissionais que trabalhavam apenas pela sobrevivência. Entretanto, outro ponto a ser considerado é que a propaganda poderia ser estrategicamente direcionada a uma parcela do nicho de mercado, focando essencialmente o público da classe média e alta carioca e consequentemente direcionando anúncios apenas com produtos de valor elevado.

A ideia em se apresentar como um estabelecimento com os menores preços da praça como atrativo aos consumidores já podia ser percebida no anúncio da Casa Carlos Werhs: "Em música, tudo: aos menores preços” e com o informe de "vendas facilitadas à longo prazo" (O VIOLÃO, n.4, 1929, p. 18).

Considerando o preço a ser investido num violão apenas um estabelecimento faz menção ao pagamento parcelado. A Casa Carlos Wehrs, na edição de dezembro de 1928 da Revista informa a novidade no meio carioca acerca da venda à prazo para os violóes Di Giorgio (O VIOLÃO, n. 1, 1928, p. 25). A edição seguinte, de janeiro de 1929 , trouxe em suas páginas uma oferta especial para facilitar a aquisição do instrumento na cena carioca. A fim de fazer vendas do instrumento a Casa anunciou o parcelamento em seis vezes e sem aumento, para seus clientes. Na ocasião, na possibilidade de desenvolver como tática de venda a reciprocidade, a Casa colocou ainda à disposição dos consumidores a experiência de prova do instrumento sem o compromisso de venda, de modo que os clientes e prospects da Casa pudessem atestar o "grande poder sonoro" do instrumento outrora recomendado pelas sumidades da arte violonística daquele tempo.

Oferta Especial - A CASA CARLOS WEHRS, o maior empório de artigos musicais da nossa Capital, desejando facilitar a aquisição dos ótimos violóes de concerto ROMEO DIGIORGIO - um instrumento perfeito e de grande poder sonoro, recomendado por 
sumidades da arte violonística como Barrios, José Rebello, Levino da Conceição, João dos Santos, João Frazão, Avelino Camargo, pelo pranteado Canhoto e muitos outros, - resolveu durante o mês de janeiro, como bonificação, fazer vendas dos violóes ROMEO DI GIORGIO em 6 prestaçóes sem aumento. A CASA CARLOS WEHRS tem o maior prazer em receber a visita de todos os amadores da arte de Tarrega e pôr a sua disposição, sem compromissos de compra os violóes de concerto ROMEO DI GIORGIO, para prova de suas qualidades de um instrumento de concerto insuperável” (O VIOLÃO, n.2, 1929, p. 4)

Um ponto de destaque é que ao ressaltar em seu convite a comunidade violonística e pôr os instrumentos à prova, seria possível considerar que não era uma prática do estabelecimento deixar os instrumentos disponíveis e acessíveis para experimentação tal qual temos nos dias de hoje?

Se considerarmos a possibilidade de que havia um padrão de vitrines nas Casas de Música e que seguissem de igual modo a cultura de organização de exposição da Loja A Guitarra de Prata (ver Fig. 2), ou seja, mantendo o salão livre, é possível conjecturar que os instrumentos não eram ou estavam acessíveis facilmente às mãos do público e dependiam continuamente que os vendedores-balconistas retirassem do expositor o modelo selecionado pelo consumidor para uma eventual prova (ver Fig. 3).

FIGURA 2 - Foto do balcão e armário expositor de instrumentos da Loja A Guitarra de Prata.

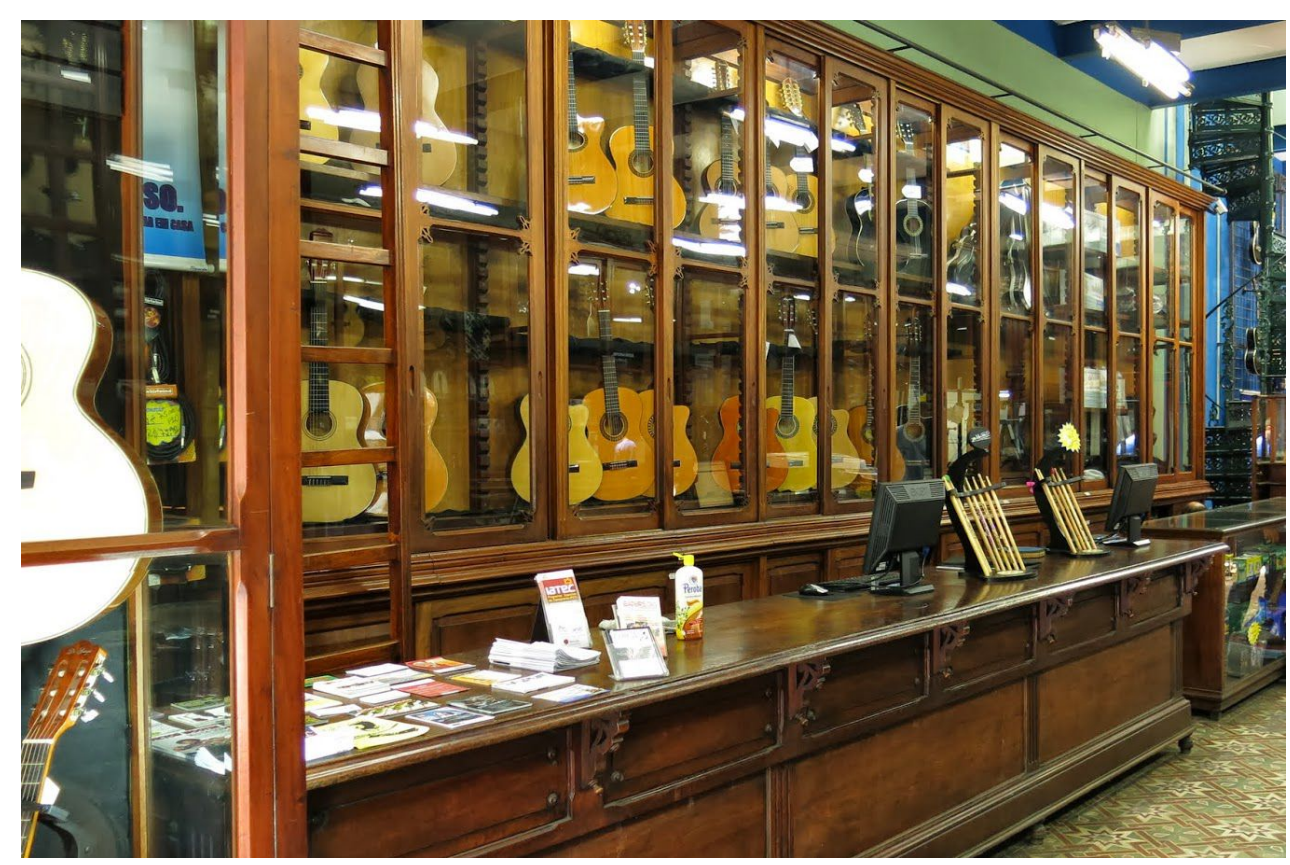

Fonte: LAMA $(2013)^{6}$

\footnotetext{
${ }^{6}$ LAMA, Rogério. Quando os gigantes caminhavam sobre a terra. Blogger Diumtudo-marvioli. <http://diumtudomarvioli.blogspot.com/2013/10/quando-os-gigantes-caminhavam-sobre_22.html> Acesso em 31.ago.2020.
} 
FIGURA 3 - Balcão da Casa Clarim Universal. Dois vendedores expondo quatro violóes. Ao fundo é possível ver o armário-vitrine como expositor dos instrumentos da casa.

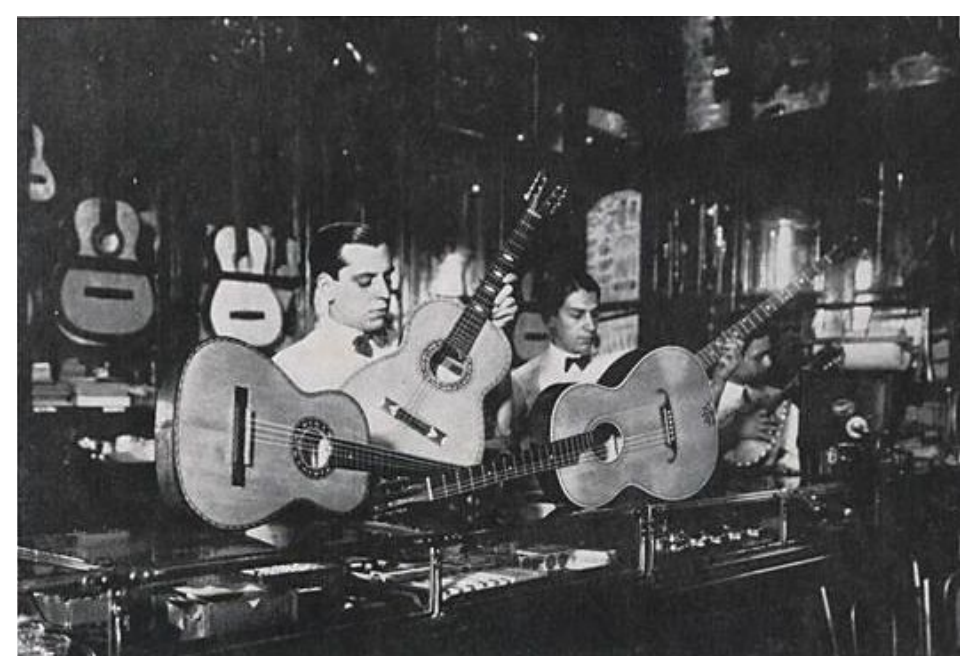

Fonte: O VIOLÃO (n. 5, 1929, p. 27)

A fim de ilustramos a ideia de valor agregado, a propaganda da Casa Carlos Werhs na primeira edição da revista nos dá um indicativo quanto ao uso da aprovação social dada pelo professor de violão Levino Albano da Conceição (1895-1955) através de uma carta em que comenta o uso do violão Di Giorgio. A Carta aberta, escrita por Levino em abril de 1928 durante a série de concertos dados no Estado de São Paulo foi publicada no anúncio da Casa para servir como referência ao público (credibilidade) acerca da qualidade sonora e pela beleza do detalhamento estético empregados na construção do instrumento (qualidade). Segue a transcrição da carta.

Vila Americana, 12 de abril de 1928.

Venho manifestar-lhe publicamente a minha grande satisfação, pelo êxito que alcancei em Vila Americana no concerto que levei a efeito e no qual executei todos os números do meu programa anunciado, com o auxilio do violão fabricado por V.S.

Todos os que ouviram e viram, não regatearam louvores ao inteligente artífice e foram unanimes em proclamar uma maravilha o violão, ao qual como disse, devo em grande parte, o meu sucesso, não somente pelo seu som admirável, senão também pelo que respeita a parte estética, pelos encrustamentos artísticos que V.S. com a sua habilidade profissional, soube aplicar, sem prejuízo da intensidade e repercussão do som de tão útil quão agradável instrumento.

Eu que já tive o prazer e a honra de ouvir e de tocar nos melhores instrumentos dos mais afamados autores do velho mundo, posso hoje dizer, sem lisonjea-lo e sem medo de errar, que se os instrumentos de V.S não supera aqueles, também em nada lhe são inferiores. Fica, pois, aqui, de volta com os meus sinceros agradecimentos, embora esta minha homenagem esteja aquém do que V.S. é merecedor. (Levino da Conceição apud O VIOLÃO, n.1, 1928, p. 25). 
Levino da Conceição encerra sua carta colocando-se como uma referência por ter tido a possibilidade de ouvir e tocar os melhores instrumentos dos autores do velho mundo e póe-se a testificar a qualidade do violão de Di Giorgio.

$\mathrm{O}$ anúncio da Casa Wehrs publicado no quarto volume da revista $\mathrm{O}$ Violão informa sobre a representação do estabelecimento na comercialização das melhores fabricantes da indústria do piano. O anúncio traz ainda informaçóes sobre o Dulcetto, o Triegon, as cordas Pirastro e os Violóes Di Giorgio.

CASA CARLOS WEHRS, fundada em 1851, o maior empório de artigos musicais. Representantes de Steinway \& Sons, Schiedmayer \& Soehne, Essenfelder, os três "reis magos” da indústria de pianos. Modelos modernos, em armário e cauda, madeira de lei, em todas as cores. DULCETTO, o super-portátil dos gramofones, em todas as cores. Preços desde $275 \$ 000$. TRIERGON, o primeiro disco Photo-eletro-record, gravado pelo novo processo de fotografia do som. Sempre novidades em todos os gêneros. Catálogo a quem pedir. VIOLÕES DI GIORGIO, o melhor violão de concerto, fabricado à mão. Enorme volume de som e macia entrastadura. PIRASTRO, a melhor corda. Para todos os instrumentos, dando 5 $\mathbf{a}$ Justa, a preferida por todos os artistas de renome mundial. Variadíssimo estoque de instrumentos de corda de e de sopro das maiores indústrias alemãs, francesas e americanas (O VIOLÃO, n.4, 1929, p. 18).

A Casa Werhs reforça seu posicionamento enquanto único representante no ano de $1928 \mathrm{da}$ fabricante de encordoamento alemã Pirastro, fundada em 1798. Esta posição durou até o fevereiro de 1929, quando O Cavaquinho de Ouro passa a anunciar a comercialização de todo o sortimento do produto em seu ponto. $\mathrm{O}$ anúncio da Casa Carlos Wehrs, publicado na edição número dois, em janeiro de 1929 ressalta

Das qualidades sonoras fibrativas das cordas de tripa, depende muitas vezes o som e a afinação rigorosa de um instrumento. Usando as célebres Cordas PIRASTRO o artista tem garantidos todos estes requisitos. As cordas PIRASTRO gozam de fama mundial e são usadas pelos maiores artistas da Europa pelos maiores artistas da Europa, Norte e Sul América. Usando uma vez, usará sempre! (O VIOLÃO, n.2, 1929, p. 4).

Até antes do desenvolvimento do nylon, em 1935, pelo químico estadunidense Wallace Hume Carothers, as cordas diferenciavam-se basicamente entre dois materiais, as de metal/arame e as de Catgut. Esta última, base das cordas Pirastro, eram produzidas a partir do processamento de uma fibra elástica natural extraída do revestimento intestinal de animais como boi, ovelha ou porco. Durante a Segunda Guerra Mundial (1939-1945) devido à altíssima demanda por suturas cirúrgicas feitas 
principalmente de intestino animal proporcionou escassez do produto para a produção de cordas. $\mathrm{O}$ luthier dinamarquês Albert Augustine (1900-1967), em 1946, contando com a colaboração do violonista Andrés Segóvia, foi o primeiro fabricante a produzir comercialmente encordoamentos à base de nylon para violão. $\mathrm{O}$ material mostrou-se mais eficiente na projeção de volume, sustain e afinação do que as cordas de Catgut.

Outro anúncio passível de destaque é quanto a seleção do repertório para violão anunciado pela Casa Arthur Napoleão na quarta e oitava edições do periódico (ver Tabela 3). A primeira série conta principalmente com obras transcritas por Francisco Tarrega (1852-1909), Mario Rodriguez Arenas (1879-1949) e Andrés Segóvia (1893-1987). Nessa tabela encontra-se referência a edição do Choros no 1 (1920), de Heitor Villa-Lobos ao preço de $3 \$ 000$ réis. O valor pode ser considerado alto se levarmos em consideração que no segundo volume da Revista O Violão, os leitores consideraram demasiadamente caro uma publicação que custasse $5 \$ 000$ réis (O Violão, n. 2, jan. 1929). Entretanto, cabe considerar que o preço d'O Violão era excessivamente alto se comparada às revistas de atualidade e ilustrada do período. Porém, era extremamente barato para uma publicação que ofertou em média 5 obras, mais orientações e exercícios técnicos da Escola de Tarrega em cada volume.

TABELA 3 - Casa Arthur Napoleão, músicas para Violão

\begin{tabular}{lccc}
\hline Compositor & Transcrição & Obra & Preço \\
\hline Chopin & Tárrega & Noturno no2 & $4 \$ 000$ \\
Bach & Tárrega & L'oure & $4 \$ 000$ \\
Beethoven & Tárrega & Scherzo - Sonata op. 2 & $4 \$ 000$ \\
Beethoven & Tárrega & Fuga - Sonata n. & $7 \$ 500$ \\
Mozart & Tárrega & Minuet & $4 \$ 500$ \\
Mozart & Tárrega & Minuet Du Quatour & $4 \$ 500$ \\
Schumann & Tárrega & Saint Nicolas & $4 \$ 500$ \\
Schumann & Tárrega & Feuilles Variees & $4 \$ 000$ \\
Schumann & Tárrega & Fuga & $4 \$ 000$ \\
Tarrega & - & Minueto & $3 \$ 000$ \\
Tarrega & - & Dois prelúdios - no 8 e 9 & $3 \$ 000$ \\
Schubert & Arenas & Momento Musical no3 & $3 \$ 000$ \\
Carulli & - & 3 sonatas & $4 \$ 000$ \\
Diabelli & - & 30 peças fáceis & $6 \$ 000$ \\
Sor & - & 20 Valsas escolhidas & $6 \$ 000$ \\
Cezar-Frank & Segóvia & 4 peças & $4 \$ 000$ \\
Mozart & Segóvia & Minuet & $4 \$ 000$ \\
Ponce & Segóvia & Tema variado & $6 \$ 000$ \\
\hline
\end{tabular}


TABELA 3 - (cont.) Casa Arthur Napoleão, músicas para Violão

\begin{tabular}{lccc}
\hline Compositor & Transcrição & Obra & Preço \\
\hline Ponce & Segóvia & Sonata no 3 & $7 \$ 500$ \\
Torroba & Segóvia & Prelúdio & $4 \$ 500$ \\
Villa-Lobos & - & Choros no1 & $3 \$ 000$ \\
\hline
\end{tabular}

Fonte: O VIOLÃO (n.4, 1929, p. 23)

O segundo anúncio (ver Tabela 4) conta com os já tradicionais compositores de estética classicista que escreveram para o instrumento como Matteo Carcassi (1792-1853), Ferdinando Carulli (1770-1841), Mauro Giulianni (1781-1829), Fernando Sor (1778-1839); constam ainda dois compositores alemães, Joseph Küffner (1776-1856) e Hermann Gustav Göetz (1840-1876); dois compositores argentinos, Julio Salvador Sagreras (1879-1942) e Mario Rodriguez Arenas; o musicólogo espanhol Eduardo López-Chávarri (1871-1970) e o compositor associado ao repertório segoviano Frederico Moreno Torroba (1891-1982). Na canção Andorinhas, observa-se a publicação do acompanhamento para violão feito por Joaquim Francisco dos Santos, o Quincas Laranjeiras (1873-1935).

TABELA 4 - Casa Arthur Napoleão, músicas para Violão.

\begin{tabular}{lccc}
\hline Compositor & Transcrição & Obra & Preço \\
\hline Arenas & - & Natal de Pierrot - Andantino & $3 \$ 500$ \\
Carcassi & - & Op. 21, 24 pequenas peças & $7 \$ 500$ \\
Carcassi & - & Op. 60, 25 Estudos melódicos & $6 \$ 000$ \\
Carulli & - & Andante, Prelúdio, Siciliana e estudo & $2 \$ 500$ \\
J. Casado & Chrysanthemo & Valsa & $2 \$ 000$ \\
J. Casado & Chrysanthemo & Aguenta firme - foxtrote & $2 \$ 000$ \\
J. Casado & Chrysanthemo & Nhapope - canção & $2 \$ 000$ \\
Chavarri & - & Música moderna espanhola - Álbum & $7 \$ 500$ \\
& - & 7 peças & \\
Giulianni & - & Capricho e Alegretto & $2 \$ 000$ \\
Kuffner & - & 9 Primeiras pequenas peças & $2 \$ 000$ \\
Göetz & - & Quadro de cadências em todos os tons & $3 \$ 000$ \\
Sagreras & - & Cavallaria rusticana - Intermezzo & $2 \$ 000$ \\
Sagreras & - & La tararira - Mazurka & $3 \$ 000$ \\
Sor & - & 20 Minuetos escolhidos & $6 \$ 000$ \\
Tarrega & - & Mazurka & $6 \$ 000$ \\
\hline
\end{tabular}

\footnotetext{
${ }^{7}$ Não conseguimos localizar referências que nos permitissem identificar o compositor.

${ }^{8}$ Detalhamento sobre a composição do álbum com 7 peças: I - Danza Lenta; II - Ritmo popular; III - Fiesta lejana en un jardin; IV - Nocturno; V - La mirada de Carmen; VI - Lamento; VII - Gitana. Disponível em: $<$ https://www.sheetmusicplus.com/title/7-pieces-sheet-music/6066272?ac=1\&aff_id=50330>. Acesso em: 31 ago 2020 .
} 
TABELA 4 - (cont.) Casa Arthur Napoleão, músicas para Violão.

\begin{tabular}{lccc}
\hline Compositor & Transcrição & Obra & Preço \\
\hline Tarrega & - & Fuga de Schumann & $4 \$ 500$ \\
Torroba & - & Suite Castellana & $4 \$ 500$ \\
Villa-Lobos & - & Choros no 1 & $3 \$ 000$ \\
L. Fernandez & Acompanhamento & Andorinhas - Canção & $2 \$ 500$ \\
& de Joaquim F. dos & & \\
& Santos & & \\
\hline
\end{tabular}

Fonte: O VIOLÃO (n.8, 1929, p. 29)

O anúncio da Casa A Guitarra de Prata sobre o violão modelo Robledo (ver Fig. 4) informa que é um instrumento de elite para a elite. A marca direciona o produto ao público feminino, informando que o Robledo é “modelado em proporções técnicas e de lavor sóbrio. É um tipo muito perfeito para o belo sexo e satisfaz sempre tanto os mestres como os discípulos”. Sendo um instrumento em homenagem a concertista, discípula de Tarrega e que teve forte presença no ensino do instrumento no eixo Rio-São Paulo, a marca dá a entender que o instrumento não se destina apenas aos mestres.

Diante de uma praça comercial ampla e que dispunha em seus estabelecimentos, oficinas de fabricação de instrumentos é de se supor que se fabricavam cópias de instrumentos. Talvez, por isso, a marca chame a atenção do consumidor ao informar que o modelo é exclusivo da loja, ressaltado uma característica que o instrumento traz em seu interior: "o rótulo representando a exímia violonista executando no seu instrumento”.

FIGURA 4 - Anúncio do violão modelo Josephina Robledo fabricado pel’A Guitarra de Prata.

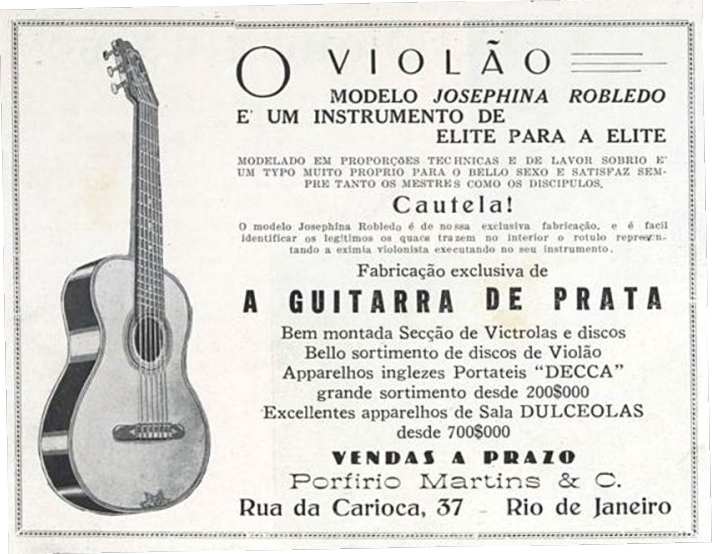

Fonte: O VIOLÃO (n.6, 1929, p. 12). 
A figura a seguir nos permite visualizar três modelos produzidos pela Casa A guitarra de Prata, "a trindade sonora": Carioca, Robledo e Valenciano (ver Fig. 5) fabricados pela própria casa. A propaganda reforça a excelência da sonoridade e o acabamento “perfeito” dos instrumentos. A Casa dispunha de um modelo próprio com shape body Valenciano tal qual a Casa O Cavaquinho de Ouro.

FIGURA 5 - Anúncio d'A Guitarra de Prata com destaque no canto superior esquerdo para os modelos Carioca, Robledo e Valenciano.

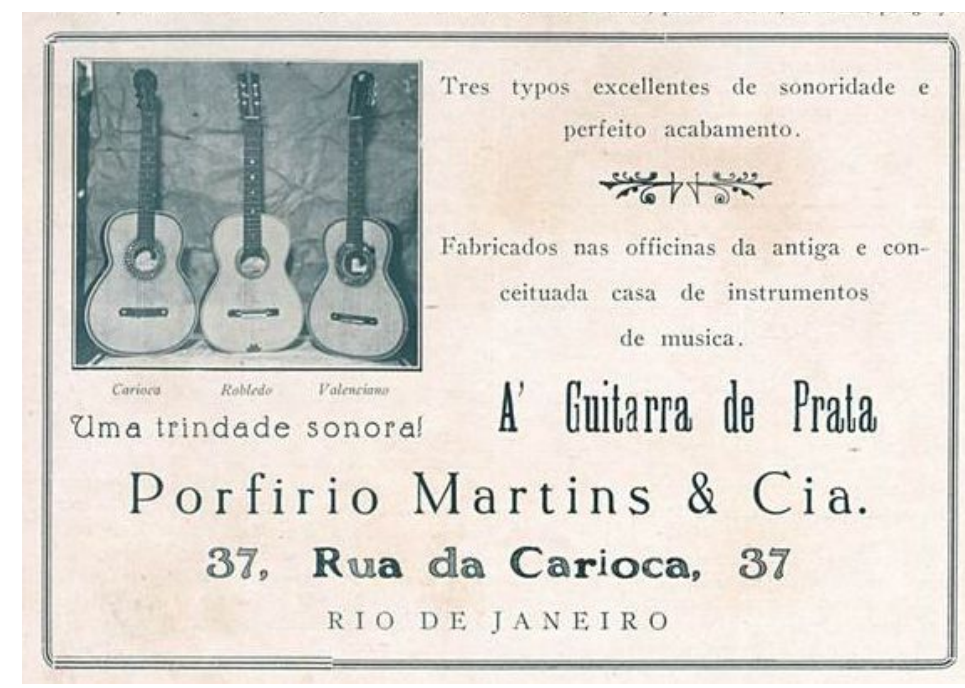

Fonte: O VIOLÃO (n.2, 1929, p. 16)

\section{CONSIDERAÇÕES}

À luz dos 4P do Marketing - Produto, Praça, Promoção e Preço - buscamos analisar o conjunto de peças publicitárias publicadas ao longo das ediçốes da Revista O Violão. Enquanto fonte documental imagética, as propagandas foram analisadas a fim de reconhecermos o público-alvo e as ideias que estavam em propagação para a comunicação com os consumidores. As ideias de confiança, credibilidade e qualidade permeiam os anúncios e visavam gerar uma percepção que conectasse o consumidor aos produtos em promoção. Desse modo, cabe recobrarmos as questóes que lançamos inicialmente: que crenças, princípios, opinióes e valores as peças publicitárias sobre violão pretendem transmitir nesta revista? O uso de violonistas manifestando sua opinião ou associação à marca traduzem a ideia de credibilidade e a confiança que o artista deposita no produto. A qualidade aparece constantemente associada à excelência e a primazia do acabamento. A revista, de fato, não direciona 
especificamente em suas páginas a quem ela se dirige em termos de classe social. Entretanto, as matérias, os conteúdos musicais, as fotos de leitores, as reportagens de eventos e as propagandas nos permitem percorrer uma trilha de vestígios quando associados às terminologias adjetivas de recursos financeiros, adotadas pelo periódico.

Como podemos ver, por mais que a revista buscasse um alcance amplo, visando atender diferentes micronichos afeitos ao estudo do violão, mesmo que para isso abrisse concessão para outras metodologias de ensino, o foco estava em direcionar os seus leitores aos fundamentos da Escola de Tarrega, uma das chaves para dar legitimidade e notoriedade ao instrumento: o "estudo sério".

Que signos as propagandas comportaram e que nos permitiram alcançar o público-alvo da revista $\mathrm{O}$ Violão? A qualidade dos produtos, a localização dos estabelecimentos, a forma de promoção publicitária e os valores constitutivos de preço nos permitem crer que $\mathrm{O}$ Violão estava associado às classes mais abastadas da sociedade carioca. Se a ideia era elevar o instrumento aos salóes, divulgar uma técnica violonística europeia, reportar eventos da elite com a presença do instrumento, expor um padrão de repertório e compositores da música concerto, as crenças e posicionamentos da revista revelam-se extremamente coerentes e a abertura de espaço para venda de publicidade em suas páginas dialoga com itens que aparentemente poderiam ser desejados por todos, mas consumidos por poucos, ou seja, apenas pelas classes mais abastadas.

Que informações podemos ainda extrair acerca do mercado de vendas em torno do violão no centro da cidade do Rio de Janeiro? A praça d’O Violão representa uma parcela da totalidade de estabelecimentos musicais em funcionamento na cidade no ano de 1929. Logo, os preços atrelados aos produtos pontuados pelas propagandas eram preços praticados de modo geral pelo mercado ou podemos considerar que eram preços associados a uma faixa de produtos de ponta com acabamento luxuoso e consequentemente praticados apenas pela praça d'O Violão? Se nos apegarmos à segunda hipótese, a revista, juntamente com estes estabelecimentos, compartilhou uma carta selecionada de produtos de modo a atender as especificidades financeiras do público-alvo. Caso a primeira hipótese prevaleça pela associação com outras fontes de pesquisa, outra pergunta surge no horizonte: o violão, realmente, estava ao alcance de todos no Rio de Janeiro? 


\section{REFERÊNCIAS}

CASAS, A. L. Marketing de serviços. 5a Ed. São Paulo: Atlas, 2007.

CERTEAU, Michel. A Invenção do cotidiano: a arte de fazer. 3a Ed. Petrópolis: Editora Vozes, 1998.

CZINKOTA, Michael; DICKSON, Peter; DUNNE, Patrick; GRIFFIN, Abbie. Marketing: as melhores práticas. Porto Alegre: Bookman, 2002.

FERREIRA, Aurélio Buarque de Holanda. Minidicionário da língua portuguesa. 3a Ed. Rio de Janeiro: Nova Fronteira, 1993.

KOTLER, Philip. Administração de marketing: análise, planejamento, implementação e controle. 4. Ed. São Paulo: Atlas, 1998.

LEFEBVRE, Henri. O direito à cidade. Trad. Rubens Eduardo Frias. 5ạ Ed. São Paulo: Centauro, 2011.

LOBO, Eulália Maria Lahmeyer et al. Evolução dos preços e do padrão de vida no Rio de Janeiro, 1820-1930: resultados preliminares. Revista Brasileira de Economia, Rio de Janeiro, v. 25, n. 4, p. 235-266, 1971.

MACHELINE, Claude; ROJO, Francisco J.; PSILLAKIS, Homero; FERRACCIU, João. Gestão de marketing. São Paulo: Saraiva, 2003.

MUMFORD, Lewis. A cultura das cidades. Trad. Neil R. da Silva. Belo Horizonte: Editora Itatiaia, 1961.

NICKLES, Willian; WOOD, Marian Burk. Marketing: relacionamentos, qualidade, valor. Rio de Janeiro: LTC, 1999.

RACKHAM, Neil. Alcançando excelência em vendas para grandes clientes. São Paulo: M. Books do Brasil Editora, 2011.

ROCHA, A. CHRISTENSEN, C. Marketing: teoria e prática no Brasil. 2a Ed. São Paulo: Atlas, 1999.

A Classe operária: Jornal de trabalbadores feito para trabalhadores (1925-1928), Rio de Janeiro, 31.

Mai. 1925, p.1.

O Violão, Rio de Janeiro, no 1, dez. 1928.

O Violão, Rio de Janeiro no 2, jan. 1929.

O Violão, Rio de Janeiro, no 3, fev. 1929.

O Violão, Rio de Janeiro, no 4, mar. 1929.

O Violão, Rio de Janeiro, no 5, abr. 1929.

O Violão, Rio de Janeiro, no 6, mai/jun. 1929.

O Violão, Rio de Janeiro, no 7, jul. 1929.

O Violão, Rio de Janeiro, no 8, ago./set. 1929. 
O Violão, Rio de Janeiro, no 9, out. 1929.

O Violão, Rio de Janeiro, no 10, nov. 1929.

\section{SOBRE OS AUTORES}

José Jarbas Ruas é doutorando em Música pelo Programa de Pós-graduação em Música da Escola de Música da UFRJ. É mestre e bacharel em música (violão) pela mesma instituição. Trabalha com o levantamento histórico de fontes documentais que visam remontar a trajetória do comércio musical na cidade do Rio de Janeiro. Faz parte do grupo de pesquisa Novas Musicologias e do Núcleo de Estudos do Violão (NEV). Atua profissionalmente como professor da Universidade Federal do Tocantins, no curso de licenciatura em Educação do Campo: Artes e Música, no campus de Tocantinópolis-TO. ORCID: https://orcid.org/0000-0002-7435-8684. E-mail: jiruas@uft.edu.br 